\section{Utilidad de Pruebas de cadena de polimerasa, pruebas rápidas y Tomografías en pacientes con Covid-19}

Usefulness of polymerase chain tests, rapid tests and tomography in patients with Covid-19

Johanna Mercedes Meza Calvache

Médico general. Hospital de

especialidades de las Fuerzas Armadas

N1,yohamercedes@hotmail.es,

https://orcid.org/0000-0003-4157-

3043. Guayaquil, Ecuador

Alex Daniel Estrada Rodríguez

Médico general. Seguro Social

Campesino de Los Ríos,

alex89_daniel@hotmail.es,

https://orcid.org/0000-0002-7859-

9418. Guayaquil, Ecuador

Carlos Bismark Chabusa Martínez

Médico general. Odontomedica San

Eduardo, carloschabusam@gmail.com,

https://orcid.org/0000-0002-5923-0201

Guayaquil, Ecuador

Victor Alfonso Velasco Paucar

Médico general. Centro de Salud San

Buenaventura, croso08@hotmail.com,

https://orcid.org/0000-0001-7549-

5579. Guayaquil, Ecuador

http://www.jah-journal.com/index.php/jah Journal of American health

Julio - Diciembre vol. 3. Num. 2 - 2020

Esta obra está bajo una Licencia Creative

Commons

Atribución-NoComercial-CompartirIgual

4.0 Internacional.

RECIBIDO: 30 DE MARZO 2020

ACEPTADO: 23 DE MAYO 2020

PUBLICADO: 2 DE JULIO 2020

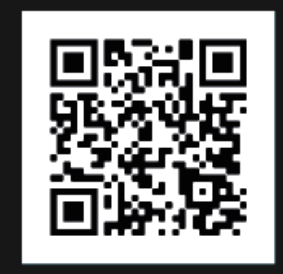

scan this QR

code with your

smart phone or

mobile device to

read more papers

\section{RESUMEN}

En la actualidad existe un sinnúmero de métodos diagnósticos para Covid-19 desde pruebas para la detección de virus algunos con ventajas sobre la sensibilidad, especificidad y otros con desventajas sobre costos, infraestructura, personal sanitario capacitado para aplicarlos, si bien el procedimiento de elección es una técnica molecular de detección y amplificación de ácidos nucleicos o material genético como el RT-PCR, también es necesario disponer de pruebas rápidas, simples e idealmente con alta sensibilidad y precisión que se puedan realizar a gran escala para brindar un diagnóstico precoz, realizar un mejor manejo clínico, epidemiológico de los pacientes. No obstante todas tienen sus limitaciones por esto es importante evaluar el rendimiento de las pruebas ya existentes, calificar cuál de estas es la mejor opción diagnóstica en base al análisis de los estudios públicados y de acuerdo a la realidad de cada estructura sanitaria sustituir la RT-PCR para aplicarse en los hospitales. Métodos menos invasivos, más accesibles con menor carga económica como la tomografía axial computarizada de tórax pueden ser otras opciones, las alteraciones pueden estar presentes incluso en estadios iniciales especialmente en pacientes de riesgo, además de los moderados y severos, presentan patrones ya establecidos de acuerdo a la gravedad que permiten incluso puntuarlas, además de método diagnostico muy sensible, es importante su uso para el manejo de las complicaciones de Covid-19 como el tromboembolismo pulmonar así como seguimiento de los casos diagnosticados, disminuyendo las tasas de morbimortalidad y las complicaciones por esta causa. Realizar un diagnósticos precoz para tratamiento adecuado y oportuno es 
fundamentales para guiar las decisiones sanitarias en el contexto de covi-19.

PALABRAS CLAVE: RT-PCR, TAC tórax, pruebas rápidas, anticuerpos

\section{ABSTRACT}

Currently, there are countless diagnostic methods for Covid-19, from tests to detect viruses, some with advantages over sensitivity, specificity and others, with disadvantages regarding costs, infrastructure, trained health personnel to apply them, although the procedure of choice. is a molecular technique for detection and amplification of nucleic acids or genetic material such as RT-PCR, it is also necessary to have rapid, simple and ideally tests with high sensitivity and precision and that can be performed on a large scale to provide an early diagnosis, perform better clinical and epidemiological management of patients. However, all of them have their limitations, so it is important to evaluate the performance of existing tests, to qualify which of these is the best diagnostic option based on the analysis of published studies and according to the reality of each health structure so that it replaces the RT-PCR and apply in your hospitals. Less invasive, more accessible methods with less economic burden, such as computed tomography of the chest, may be other options where patterns of chest CT indicate diagnostic probabilities even in initial stages, in addition to moderate and severe ones, with typical patterns according to their severity, which even allows scoring them, in addition to being a very sensitive diagnostic method, its use is important for the management of Covid-19 complications such as pulmonary thromboembolism and patient follow-up, reducing the complications that put the risk at risk. patient life, lower morbidity and mortality rates, and improve quality of life, everything is of fundamental importance to guide health decisions.

KEYWORDS: RT-PCR, chest CT, rapid tests, antibodies

\section{INTRODUCCIÓN}

La evidencia científica demuestra que el $80 \%$ de los pacientes con Covid-19 son asintomáticos, y existe la posibilidad de que este grupo de personas infectadas con SARS-CoV-2 eliminen y transmitan el virus lo que indica que el diagnóstico temprano para el tratamiento y control de la infección por coronavirus es crucial, entre los síntomas clínicos más frecuentes destaca la fiebre, tos, mialgia. Sin embargo, no son características únicas de COVID-19 ya que pueden ser similares a los observados en otras enfermedades virales (1). En la actualidad existe mucha información alrededor de métodos diagnósticos para COVID-19, entre los test destacan los RTPCR real time, los test de anticuerpos y los test de antígenos del COVID-19. Estos incluyen pruebas de enzimoinmunoensayos (ELISA), Inmunofluorescencia y otras metodologías como LAMP y cultivos celulares y dentro de las imágenes destacan la TAC de Tórax.

Los genes diana más usados en RT-PCR para la detección de SARS-CoV-2 son el gen E, el gen $\mathrm{RdRp}$, para estudio de confirmación y el gen $\mathrm{N}$ para estudio adicional de confirmación, otro gen usado es el Orf1ab entre los métodos (2). Estos incluyen pruebas de enzimoinmunoensayos (ELISA), Inmunofluorescencia y otras metodologías como LAMP y cultivos celulares (3) 
No obstante la baja sensibilidad de ciertos métodos implica que un "gran número de pacientes con Covid-19 no serán identificados rápidamente y pueden no recibir el tratamiento adecuado.

El PCR en tiempo real es el Gold estándar y método más empleado, sin embargo tiene algunas desventajas es costoso, necesita personal experto en Microbiología molecular y medidas de bioseguridad, equipos y personal específico, además tiene un porcentaje relativo de falsos negativos.

En comparación con la PCR, la tomografía computarizada de tórax puede ser un método más fiable, práctico y rápido para diagnosticar y evaluar el COVID-19, especialmente en el área de la epidemia"; Según un estudio con 1.000 pacientes que se ha publicado en la revista 'Radiology' la tomografía computarizada (TC) de tórax es mejor que las pruebas de laboratorio para el diagnóstico de coronavirus o COVID-19. (4), demostró tener una sensibilidad del $88 \%$ (en 1014 pacientes) y en otro 98\% en caso de COVID-sospechosos aumentando al $97 \%$ en casos asociados a PCR positiva.

Las pruebas serológicas analizan el componente sérico de la sangre que incluye anticuerpos contra componentes específicos de los patógenos, que son los antígenos los cuales son reconocidos por el sistema inmune como extraños dirigidos por la respuesta inmune del individuo. Se usa en infecciones virales para conocer si tiene una respuesta inmune a un patógeno de interés, como en este caso el coronavirus, destacan las pruebas de neutralización, inmunoflorescencia y Elisa, Wester blot, cromatografía (test rápido), reacción de amplificación (5); cuya sensibilidad para estos test serológicos rápidos (Prueba de anticuerpos combinados IgG-IgM de COVID-19 son variables, observando sensibilidad del 88,6\% y especificidad del $90,63 \%(6)$. No obstante también se ha referido sensibilidad que no llega al $48 \%$.

Actualmente, el ácido nucleico del virus por PCR a tiempo real, la tomografía computarizada y algunos parámetros hematológicos son las herramientas principales para el diagnóstico clínico de la infección cada una de ellas tiene su valor para el diagnóstico.

En virtud de lo mencionado se pretende establecer la utilidad de estos métodos diagnósticos a través de una revisión documental corroborando las ventajas y desventajas de ellas.

\section{MATERIALES Y MÉTODOS}

Estudio descriptivo documental cuyos datos fueron recolectados a través de fuentes secundarios en revistas indexadas, libros, bases de datos bibliográficas como PubMED, TripDataBASE, Cochrane. Se profundizó la búsqueda de literatura gris en buscadores genéricos, se revisaron guías e informes de OMS y OPS. Se exploraron sitios de agencias de Evaluación de Tecnologías Sanitarias, Ministerios de Salud de Argentina, Brasil, EEUU, y agencias reguladoras de dispositivos médicos publicados en los últimos cinco años 2015 al 2020 salvo los de relevancia científica de años previos, utilizando las palabras claves RT PCR, Anticuerpos, pruebas rápidas, TAC de tórax, ventajas, se escogió entre los idiomas el inglés y español se descartaron otros; los que de acceso a texto completo seleccionado 21 artículos relevante para alcanzar el objetivo de esta investigación, y se describe las ventajas y desventajas del uso de estas pruebas para diagnosticar SARS-CoV-2 a fin demostrar la utilidad de cada una de estos métodos. 


\section{RESULTADOS}

En este apartado se resume las ventajas y desventajas de las RT-PCR, TAC de tórax y las pruebas rápidas para detectar anticuerpos.

\section{Tabla \# 1: Ventajas y desventajas de las pruebas diagnósticas para covid-19}

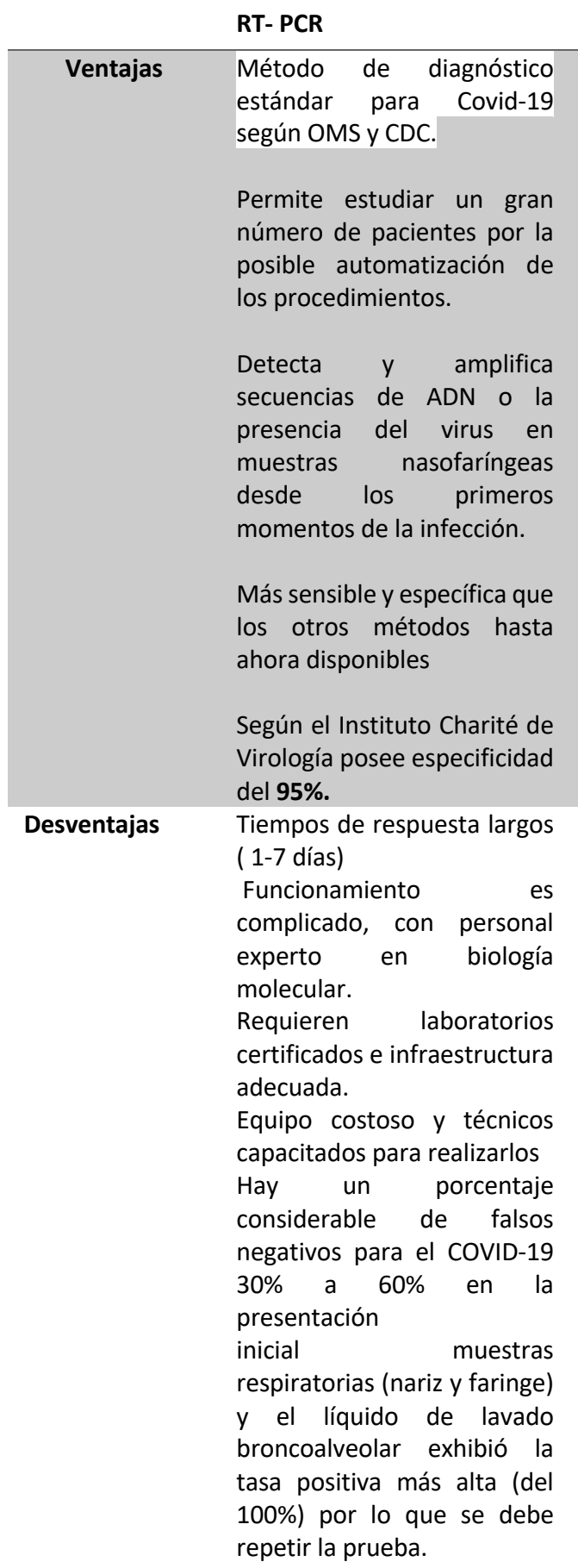

TAC de Tórax

La sensibilidad, especificidad

y precisión de la TC de tórax

para determinar la infección

por COVID-19 es de $97 \%$ y

$98 \%$.

Resultados rápidos.

Evalúa progresión de la

enfermedad.

Manejo ciertas

complicaciones causas por

Covid-19 TEP.

\section{Accesible, menor costo.}

No invasiva

Podía ser negativa para la neumonía viral por COVID-

19 como presentación inicial.

Subjetivo de acuerdo a los especialistas
IGG E IGM-AC

Sensibilidad del $88,66 \%$, especificidad del $90,63 \%$. (1).

Resultado rápido en 15 minutos.

No requiere un equipo específico ni complejo, simple de realizar y solo requería un entrenamiento mínimo.

Complementan a los estudios de RTPCR

Económica

Uso a gran escala

Tiempos de respuesta después la primer semana.

IgG e IgM contra el SARS-CoV-2 será una indicación de infección (que no discrimina si es activa o pasada), reactividad cruzada con otros coronavirus y con el virus de la gripe errores diagnósticos

Insuficiente sensibilidad y especificidad

El resultado negativo de IgM y de IgG no excluya que el paciente esté infectado por SARS-CoV-2.

Aunque se puede tomar muestras a gran escala, difícil procesar muchas muestras en un corto periodo de tiempo (5).

Deben ser validados, podrían tener un muy importante porcentaje de falsos negativos y positivos, y no garantizan inmunidad.

Escasez de suministros. 
Período de ventana de 4 o 5

días post infección.

Puede haber falsos negativos

y falsos positivos

Observaciones Baja carga viral del paciente,

/Razones muestreo clínico incorrecto;

Los resultados dependen de las casas

Variación en la tasa de

detección de diferentes

fabricantes.

Fuente: (1); (7), (8), (9), (10), (11), (12) (6)

\section{DISCUSIÓN}

El aislamiento del virus se puede lograr a partir de cultivos celulares, y las pruebas rápidas de antígeno, la serología se implementan activamente en la vigilancia epidemiológica o se están probando actualmente para su uso en el punto de atención (13).

Según la publicación en el 2020 por RedARETS la sensibilidad y valor predictivo negativo para RT- PCR son elevados, pero no son del $100 \%$ especificas, por lo que, un resultado negativo ante un paciente con elevada sospecha clínica y epidemiológica, debe repetirse. También debemos recordar que las muestras de hisopado nasofaríngeo presentan menos sensibilidad que las muestras traqueo-bronquiales (3).

En un estudio de 205 pacientes con infección confirmada por COVID-19, la positividad de RTPCR fue más alta en muestras de lavado broncoalveolar fue de (93\%), seguida de esputo (72\%), torunda nasal (63\%) y torunda faríngea (32\%), lo que puede genrar variabilidad en los resultados incluso por estos métodos diagnósticos (14).

Por otro lado, la evaluación de desempeño de una prueba serológica debe hacerse en condiciones reales de uso, para el empleo de estas en el ámbito epidemiológico, la SEIMC (Sociedad Española de Enfermedades Infecciosas y Microbiología Clínica) recomienda que estas pruebas deben evidenciar un desempeño de sensibilidad de al menos el $70 \%$ en escenarios epidemiológicos con alta prevalencia de enfermedad (5).

Asimismo, los ensayos serológicos para detectar anticuerpos (IGM, IGG) contra el SARS-CoV-2 como están rápidamente disponibles y serán críticos para estimar la prevalencia de infecciones, incluso las asintomáticas, sin embargo, actualmente es prematuro usar tales ensayos para determinar estándares de rendimiento, que incluyen sensibilidad y especificidad, por el potencial de reactividad cruzada con otros coronavirus, pudiendo generar más falsos positivos que verdaderos positivos. Este fenómeno puede complicar la interpretación clínica y epidemiológica de los resultados contra el SARS-CoV-2 que aún no se ha definido (15). Es decir que este tipo de pruebas hasta el momento no se recomiendan para el diagnóstico, dado el amplio período de ventana (7-10 días), estas pruebas pueden servir de cribado o tamizaje a personas sintomáticas con antecedentes de contacto y para levantar el perfil de seroprevalencia de la población (16). Sin embargo debido a la urgencia, y necesidad de tomar decisiones frente a un gran número de población afectada. (17), y se puede aplicar en el ámbito clínico-terapéutico, Investigación epidemiológica, Investigación clínica, Tamizaje. 
En un estudio con 397 casos positivos confirmados con PCR y 129 controles negativos (2) mostró una sensibilidad total de $88.66 \%$ y especificidad de $90.63 \%$ para las pruebas rápidas, no se puede descartar que den falsos positivos ante la presencia de anticuerpos formados contra otros virus respiratorios.

Las inmunoglobulinas $M$ (IgM) que se generan al principio, y representan un proceso de infección aguda, y las inmunoglobulinas $G(\operatorname{IgG})$, más abundantes, indicativos de infección primaria o que aparecen como respuesta a la fase aguda de infecciones secundarias. En definitiva, los tests serológicos pueden proporcionar información valiosa respecto a una infección activa o a un contagio previo (18). Pueden ser útiles para confirmar la respuesta inmunológica a un patógeno perteneciente a un grupo específico de virus, como por ejemplo los coronavirus, (19) puede suponer ciertos errores diagnósticos, dependiendo de la etapa en la que se diagnostique. Li y cols sugieren que la combinación de RT-PCR del ARN y la prueba de anticuerpos IgM-IgG puede proporcionar un diagnóstico de infección por SARS-CoV-2 más preciso.

Guo L, 2020 por su lado enfatiza que diagnóstico falso negativo puede tener graves consecuencias, especialmente en esta etapa de la pandemia al permitir que los pacientes infectados propaguen la infección y obstaculicen los esfuerzos para contener la propagación del virus (20).

Además de las pruebas en busca de detección del virus otras opciones como la Tac de tórax es otra método diagnostico prometedor especialmente en países con bajos recursos económicos, donde existen limitaciones en la infraestructura de los laboratorios o las pruebas no abastecen la demanda, una investigación reciente descubrió que la sensibilidad de la TC para la infección por Covid-19 era del 98 por ciento, en comparación con la sensibilidad de la PCR del 71 por ciento. (6).segun la revista Radiology de 1.014 pacientes, 601 pacientes (59\%) tuvieron resultados positivos de PCR, y 888 (88\%) en la TC de tórax. La sensibilidad de la TC de tórax fue del 97 por ciento, basada en los resultados positivos de PCR. En los pacientes con resultados negativos de PCR, el 75 por ciento (308 de 413 pacientes) tuvieron resultados positivos en la TC de tórax. De estos, el 48 por ciento se consideraron casos altamente probables y el 33 por ciento como probables. (4).

Otra revisión sistemática elaborada por Giuseppe Pascarella en el 2020 señala que Los hallazgos de la tomografía computarizada son importantes tanto para el diagnóstico como para el seguimiento (21).

La literatura también destaca nuevas técnicas de inmuno-ensayo basadas en anticuerpos, los sensores biomoleculares basados en papel y los recientes y prometedores métodos basados en el sistema CRISPR-Cas para detectar los ácidos nucleicos virales se siguen desarrollando.

Sin embargo Lui R.F concluye que las características clínicas, las imágenes de tórax y las pruebas de etiología basadas en genes virales RT-PCR e inmunología (pruebas rápidas y de ELISA) deberían combinarse para tener una mayor certeza de confirmar tantos los verdaderos positivos como los verdaderos negativos (7).

\section{CONCLUSIONES}


El diagnóstico de las infecciones por covid19 en fase aguda implica la detección del microorganismo por métodos directos como los métodos moleculares para la detección del material genético (ARN) viral del SARS-CoV-2 mediante técnicas de PCR o utilizando métodos indirectos como la serología en búsqueda de anticuerpos en consideración a la urgencia, y necesidad de tomar decisiones frente a un gran número de población afectada considerando las pruebas de acuerdo a los días de evolución de la enfermedad y comorbilidades del paciente.

Los resultados respaldan el uso de la Tomografía axial computarizada de tórax para la detección de COVD-19 en pacientes con características clínicas y epidemiológicas compatibles con la infección por COVID-19 particularmente cuando las pruebas de RT-PCR son negativas o cuando los recursos para la realización de pruebas mas costosas son limitados.

Sin embargo en lo posible se debe combinar los hallazgos de la RT-PCR con datos clínicos y epidemiológicos (probabilidad de exposición, síntomas y signos) y la radiología torácica (la más sensible es el TAC), ya que las alteraciones radiológicas en el COVID-19 son a veces más precoces que la positividad de la RT-PCR.

El test diagnóstico ideal debería ser rápido, fácil de procesar, ser sensible, específico, con buenos valores predictivos de acuerdo a la prevalencia, ser inocuo, ser económico y factible de conseguir en las cantidades necesarias y en forma sostenida.

\section{REFERENCIAS}

1. Li Z YYXLNX,YL,SL. Development and Clinical Application of A Rapid IgM-IgG Combined Antibody Test for SARS-CoV-2 Infection Diagnosis. J Med Virol. 2020 Feb 27.

2. Asociación Española de Pediatría de Atención Primaria. Pruebas diagnosticas de laboratorio de covid-19. [Online].; 2020 [cited 2020 Mayo 19. Available from: https://www.aepap.org/sites/default/files/documento/archivosadjuntos/pruebas_diagnosticas_de_laboratorio_de_covid_vfinal.pdf.

3. RedARETS. Diferentes tipos de tests y estrategias diagnostica en el contexto covid-19. Buenos Aires; 2020.

4. Infosalus. La tomografía de tórax es la mejor prueba para diagnosticar el coronavirus, según estudio. [Online].; 2020 [cited 2020 Marzo 28. Available from: https://www.infosalus.com/asistencia/noticia-tomografia-torax-mejor-pruebadiagnosticar-coronavirus-estudio-20200227171650.html.

5. SEIMC. [Online].; 2020 [cited 2020. Available from: https://seimc.org/contenidos/documentoscientificos/recomendaciones/seimc-rc-2020Posicionamiento_SEIMC_diagnostico_microbiologico_COVID19.pdf.

6. Sociedad Andaluza de Oftalmologia. ¿Cómo se puede Diagnosticar el COVID-19? ¿Cuál es la Precisión de los Test Diagnósticos?. Andalucia; 2020 [https://sociedadandaluzadeoftalmologia.es/como-se-puede-diagnosticar-el-covid-19cual-es-la-precision-de-los-test-diagnosticos/].

7. Liu R FADZLYLT. Promising methods for detection of novel coronavirus SARS-CoV-2. 2020. 
8. Jin YH CLCZea. A rapid advice guideline for the diagnosis and treatment of 2019 novel coronavirus (COVID-19) infected pneumonia (standard version). Mil Med Res. 2020; 7(1): p. 4.

9. J. G. Are Coronavirus Tests Flawed? 2020 Feb 13.

10 Liu R HHLFea. Positive rate of RT-PCR detection of SARS-CoV-2 infection in 4880 cases from . one hospital in Wuhan, China, from Jan to Feb 2020 [published online ahead of print. Clin Chim Acta. 2020 Marzo 7; 505: p. 172-175.

11 Chung M BAMX. CT Imaging Features of 2019 Novel Coronavirus (2019-nCoV).. Radiology, . undefined(undefined). 2020;: p. 200230. doi:10.1148/radiol.2020200230.

12 Fang Y ZHXJLMYLPPJWea. Sensitivity of Chest CT for COVID-19: Comparison to RT-PCR. . Radiology.. 2020 Feb;: p. 200432. doi: 10.1148 / radiol.2020200432.

13 Bachelet VC. Do we know the diagnostic properties of the tests used in COVID-19? A rapid . review of recently published literature. Peer-reviewed general biomedical journal. 2020; 20(3): p. DOI: 10.5867/medwave.2020.03.7891.

14 Nandini Sethuraman M, Sundararaj Stanleyraj Jeremiah M, Ryo A. Interpretación de . pruebas de diagnóstico para SARS-CoV-2. Jama. 2020 Mayo 6;: p. doi: 10.1001 / jama.2020.8259.

15 Kirkcaldy R ea. COVID-19 e inmunidad posinfección. JAMA. 2020 Mayo 11.

16 Ministerio de Sanidad. Gobierno de España. Guia para la utilizacion de test rapisdos de . Anticuerpos.; 2020.

17 Msp E. [Online].; 2020 [cited 2020 Mayo 3. Available from: https://www.salud.gob.ec/wp. content/uploads/2020/04/Protocolo-de-uso-de-pruebas-r\%C3\%A1pidas-paradetecci\%C3\%B3n-de-anticuerpos-contra-Sars-Cov-2Covid-19_v2_20_04_2020.pdf.

18 NanoB2A - ICN2. Técnicas y sistemas de diagnóstico para COVID-19:.; 2020 . [https://www.ciencia.gob.es/stfls/MICINN/Ministerio/FICHEROS/TecnicasDiagnosticoCO VID19-ICN2.pdf].

19 OMS. Pruebas de laboratorio para el nuevo coronavirus de 2019 (2019-nCoV) en casos . sospechosos de infección en humanos. 2020 Enero 17.

20 Guo L RLYSea. rofiling Early Humoral Response to Diagnose Novel Coronavirus Disease . (COVID-19). Clin Infect Dis. 2020;: p. doi:10.1093/cid/ciaa310.

21 Giuseppe Pascarella ea. Diagnóstico y manejo de COVID-19: una revisión integral. J Intern . Med. 2020 abril 29;: p. doi: 10.1111 / joim.13091. 